\title{
A rare case of Spigelian hernia combined with direct and indirect inguinal hernias
}

\author{
Murat Özgür Kılıç, Gürkan Değirmencioğlu, Cenap Dener
}

\begin{tabular}{|c|c|}
\hline ABSTRACT & $\begin{array}{l}\text { Spigelian hernia is a rare type of ventral hernias with nonspecific symptoms and signs. Therefore, its diagnosis is of- } \\
\text { ten difficult and requires more clinical attention. Although intermittent abdominal swelling and pain are the main } \\
\text { symptoms, Spigelian hernias can be sometimes asymptomatic and are discovered incidentally at the operation. In } \\
\text { some cases, these hernias can be associated with other abdominal wall hernias, therefore a detailed physical exami- } \\
\text { nation of the patients is necessary to avoid mistakes in diagnosis. Herein, we report an interesting and educational } \\
\text { case of Spigelian hernia with accompanying ipsilateral both direct and indirect inguinal hernias in a male patient } \\
\text { treated by open surgical repair with use of polypropylene mesh. }\end{array}$ \\
\hline & Keywords: Abdominal wall hernia, inguinal hernia, Spigelian hernia, ventral hernia \\
\hline
\end{tabular}

Cite this paper as: Kilıç MÖ, Değirmencioğlu G, Dener C. A rare case of Spigelian hernia combined with direct and indirect inguinal hernias. Turk J Surg 2017; 33(1): 40-42.

Department of General Surgery, Turgut Özal University School of Medicine, Ankara, Turkey

Address for Correspondence Murat Özgür Kilıç e-mail:murat05ozgur@hotmail.com

Received: 09.06.2014 Accepted: 05.10.2014 Available Online Date: 19.06.2015

(C) Copyright 2017 by Turkish Surgical Association
Available online at www.turkjsurg.com

\section{INTRODUCTION}

Inguinal hernia is one of the most common surgical disorders in general surgery practice. Indirect form of inguinal hernia is characterized by the presence of a protruding peritoneal sac through the deep inguinal ring. However, Spigelian hernia (SH) is an uncommon type of hernia with an incidence of 0.1$2 \%$ of all abdominal wall hernias (1). $\mathrm{SH}$, also known as hernia of semilunar line, is the protrusion of preperitoneal fat, peritoneal sac or intraabdominal organs through a congenital or acquired defect in the Spigelian zone. This zone is formed by the fusion of transverse abdominis and internal oblique aponeurosis, and is bounded medially by the lateral margin of the rectus muscle and laterally by the linea semilunaris. Although the Spigelian aponeurosis extends from the pubic tubercle to the costal cartilage of the eighth rib, most of SHs are located in a $6 \mathrm{~cm}$ wide region inferior to the umbilicus and superior to the interspinous line, which is called as the Spigelian hernia belt (Figure 1). However, low SH is rare and may mimic inguinal hernias. Additionally, coexistence of Spigelian and inguinal hernia is an extremely rare clinical entity. To our knowledge, there is a small number of cases of $\mathrm{SH}$ combined with inguinal hernia in the literature. Herein, we report a case of low $\mathrm{SH}$ with incidentally found coexisting ipsilateral inguinal hernia in a 62 years-old male patient.

\section{CASE PRESENTATION}

A 62-years-old-man presented with a painful abdominal swelling at the right lower quadrant of abdomen for approximately 3 years. He was retired with a medical past of umbilical hernia repair and laparoscopic cholecystectomy before 10 and 6 years, respectively, and diabetes mellitus under treatment. Abdominal examination revealed the presence of a painful, reducible bulge located between the umbilicus and right anterior superior iliac spine (Figure 2). The mass was more prominent while the patient was standing and coughing. Ultrasound (US) revealed a fascial defect, $18 \mathrm{~mm}$ in diameter, at the lateral border of the rectus muscle in the right lower quadrant with herniation of bowel loops. The hernia sac was revealed by transverse skin incision, and it was seen that there was not any sign of incarceration. On visualization of surgical area, we suspected a small swelling at the deep ring of inguinal cord. The patient was performed valsalva maneuver, and thus the presence of both direct and indirect inguinal hernia was demonstrated (Figure 3). Both inguinal region and Spigelian defect were revealed by classic steps. All hernial defects were closed with primary sutures, and then reduced into the abdomen. Lichtenstein technique was performed for inguinal hernias, and then the upper part of the patch has been extended up to the Spigelian defect, and thus all hernial defects were completely closed. The postoperative course was uneventful, and the patient was discharged on the third postoperative day. Additionally, a written consent was obtained from the patient for this study.

\section{DISCUSSION}

Most of SH occurs through the transversalis and internal oblique fascia in the lower abdomen at the lateral border of the rectus muscle. SH can be both acquired and inherited. Pediatric cases are suspected to be congenital, however adult $\mathrm{SH}$ are generally considered to be acquired. These hernias are seen most 
frequently between the ages of 50-60, and are more common in women. Although the exact etiology of $\mathrm{SH}$ is uncertain, various predisposing factors including collagen disorders, chronic obstructive pulmonary disease, constipation, aging, obesity, rapid weight loss, multiparity, trauma, ascites and previous surgery have been reported. Congenital $\mathrm{SH}$ is mostly seen in male infants, and $75 \%$ of these are associated with ipsilateral undescended testis, named as Spigelian-cryptorchidism syndrome $(2,3)$. In approximately half of the acquired $\mathrm{SH}$, there is a previous abdominal surgery. Some authors have suggested that almost $50 \%$ of patients with $\mathrm{SH}$ s had previous abdominal operations. In our patient, obesity and previous surgery likely resulted in $\mathrm{SH}$ formation. Correct diagnosis of these hernias by physical examination is unreliable, especially in obese patients. Because, $\mathrm{SH}$ originates inferior to an intact external oblique aponeurosis, and this condition usually makes its symptoms and signs nonspecific. In a retrospective study of 76 cases at the Mayo Clinic, only $64 \%$ of all SH patients could be diagnosed by physical examination (4). In another study, preoperative diagnosis was made clinically in $72 \%$ of cases (5). Therefore, a high index of suspicion and additional radiological investigations are generally required for the diagnosis of $\mathrm{SH}$. The differential diagnosis includes abdominal wall tumors, hematoma of rectus sheath, diverticulitis, appendicitis, intraabdominal abscess and masses. Although US is a largely operator-dependent radiological investigation, it is usually considered to be the first step imaging method in diagnosis due to its high properties of accessibility and repeatability. Its ability to perform real time examination while the patient performs a valsalva maneuver, is also an advantage (1). However, regarding to some authors, US has high false negative rate especially in obese patients, thus contrast enhanced computed tomography (CT) should be the imaging modality of choice (6). CT may provide more information about the hernia contents and the anatomy of the surgical area (7). Although intermittently palpable mass and pain are the most common symptoms of the patients with $\mathrm{SH}(8)$, asymptomatic cases have also been reported. Generally, these are incidentally discovered during a routine medical check-up or operations for another surgical condition. Our patient presented with a painful abdominal mass at the right-inferior side of the umbilicus. SH is prone to incarceration and strangulation due to the narrow hernia neck. In the largest series published from the Mayo Clinic, incarceration rate has been reported to be as $24 \%$ (4). Due to the high strangulation risk, surgical repair of $\mathrm{SH}$ is mandatory. However, the optimal surgical approach is still controversial. Although open hernioplasty with the use of polypropylene mesh constitutes the most frequent technique, laparoscopic approaches has been increasingly used in recent years (8). Laparoscopic treatment modalities can be transperitoneal so called intraabdominal and extraperitoneal. The violation of peritoneal layer seems to be the main advantage of TEP approach, but intraabdominal SH repair was recommended as a gold standart technique due to its technical and economic advantages in a recent study (9). Independent of laparoscopic operation type, less postoperative infectious complications, less recurrence rate, less postoperative pain, less hospital stay, and early resumption of daily activities are the main advantages of laparoscopic techniques (10). However, the laparoscopic approach requires a longer learning curve as a disadvantage. We performed open surgery to our patient because of the history of previous laparotomies. Classic open

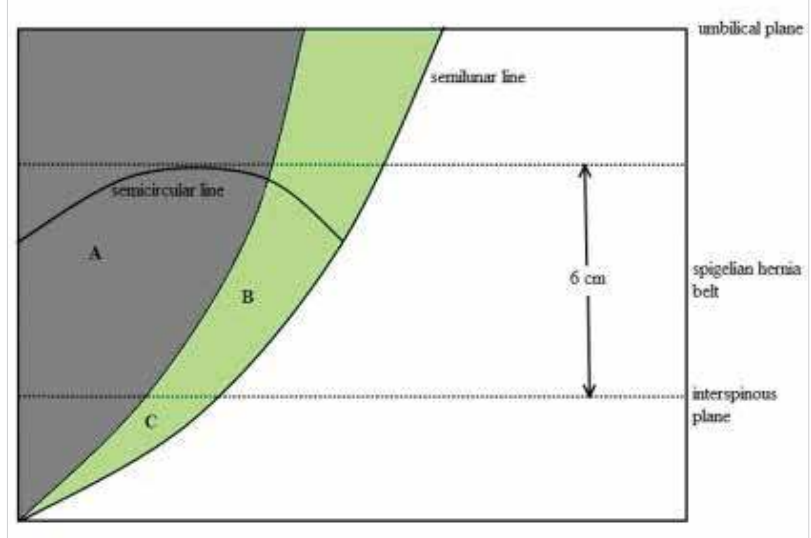

Figure 1. Illustration of the Spigelian aponeurosis (green area). A. Rectus muscle B. Area of high Spigelian hernia C. Area of low Spigelian hernia

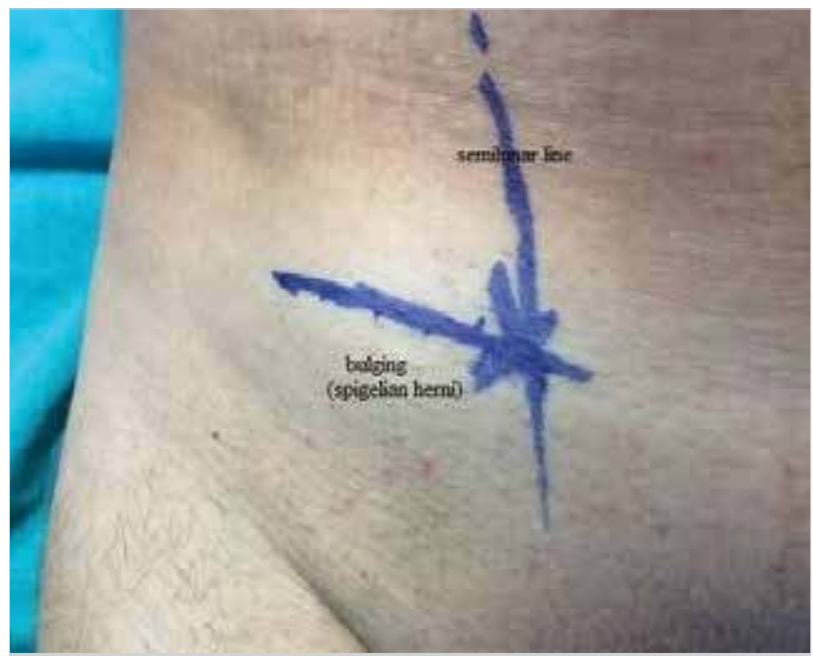

Figure 2. A bulging can be seen next to the rectus muscle. It appears especially during coughing and standing

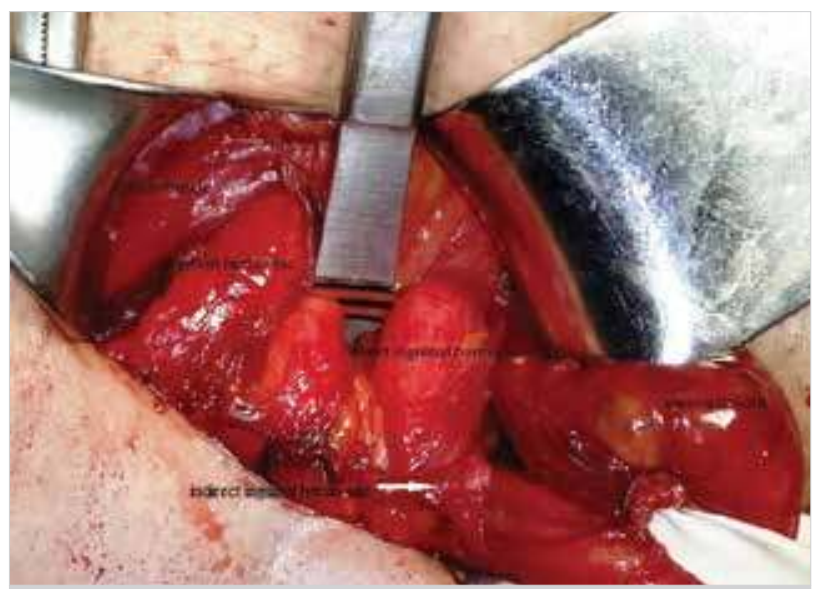

Figure 3. All-in-one view of hernias at the operation

technique can be performed with or without mesh. Primary repair can be considered for small defects, however mesh repair is appeared to be more appropriate in cases of wide defect or atrophic aponeurosis (6). In addition, open surgery is the most frequent procedure done in cases of emergency surgery (5). In our case, Spigelian defect was smaller than $2 \mathrm{~cm}$, but both Spigelian area and inguinal region were weak, and thus use of prosthesis was preferred for hernia repair. In addition, lower lo- 
Kılıç et al.

Spigelian hernia combined with inguinal hernia

calization of Spigelian hernia allowed us to use a single mesh. To our knowledge, this combined type of surgery on simultaneous inguinal and Spigelian hernias has not been reported in the literature. Additionally, we think that this technique can be preferred in appropriate cases.

Bilaterality of SH is an unusual condition. However, these hernias may be occasionally associated with other abdominal wall hernias (5). In a case series, 4 of 6 patients with SH had concomitant hernias including groin, umbilical and incisional hernias (11). Therefore, a detailed examination of all herniation sites in the abdominal wall should be required for all patients with $\mathrm{SH}$. In our case, we found both direct and indirect inguinal hernias incidentally during the operation, but it may be detected by a whole physical examination of the patient or CT preoperatively.

\section{CONCLUSION}

Spigelian hernia is an uncommon abdominal wall defect and requires a high index of suspicion in diagnosis. The presence of pain and a palpable mass in the typical location should alert the clinicians. In addition, the coexisting of SH and other abdominal wall hernias should always be kept in mind, and hence a complete evaluation of patients should be done preoperatively.

Informed Consent: Written informed consent was obtained from patient who participated in this case.

Peer-review: Externally peer-reviewed.

Author Contributions: Concept - M.Ö.K., C.D.; Design - C.D.; Supervision - C.D., G.D.; Funding - M.Ö.K., C.D., G.D.; Materials - M.Ö.K., G.D.; Data Collection and/or Processing - M.Ö.K.; Analysis and/or Interpretation - M.Ö.K.; Literature Review - M.Ö.K.; Writer - M.Ö.K., C.D.; Critical Review - M.Ö.K., C.D., G.D.
Conflict of Interest: No conflict of interest was declared by the authors.

Financial Disclosure: The authors declared that this study has received no financial support.

\section{REFERENCES}

1. Mittal T, Kumar V, Khullar R, Sharma A, Soni V, Baijal M, et al. Diagnosis and management of Spigelian hernia: A review of literature and our experience. J Minim Access Surg 2008; 4: 95-98. [CrossRef]

2. Durham MM, Ricketts RR. Congenital Spigelian hernias and cryptorchidism. J Pediatr Surg 2006; 41: 1814-1817. [CrossRef]

3. Parihar D, Kadian YS, Raikwar P, Rattan KN. Congenital Spigelian hernia and cryptorchidism: another case of new syndrome. APSP J Case Rep 2013; 4: 41.

4. Larson DW, Farley DR. Spigelian hernias: repair and outcome for 81 patients. World J Surg 2002; 26: 1277-1281. [CrossRef]

5. Ruiz de la Hermosa A, Amunategui Prats I, Machado Liendo P, Nevarez Noboa F, Muňoz Calero A. Spigelian hernia. Personal experience and review of the literature. Rev Esp Enferm Dig 2010; 102: 583-586. [CrossRef]

6. Kumar A, Garg PK, Dahiya D, Chaurasia A. Unusual disappearing abdominal bump: Spigelian hernia. Maedica (Buchar) 2013; 8: 269-271.

7. Miller R, Lifschitz O, Mavor E. Incarcerated Spigelian hernia mimicking obstructing colon carcinoma. Hernia 2008; 12: 87-89. [CrossRef]

8. Malazgirt Z, Topgul K, Sokmen S, Ersin S, Turkcapar AG, Gok H, et al. Spigelian hernias: a prospective analysis of baseline parameters and surgical outcome of 34 consecutive patients. Hernia 2006; 10: 326-330. [CrossRef]

9. Moreno-Egea A, Campillo-Soto A, Morales-Cuenca G. Which should be the gold standard laparoscopic technique for handling Spigelian hernias? Surg Endosc 2015; 29: 856-862. [CrossRef]

10. Barker R, Gill RS, Brar AS, Birch DW, Karmali S. Emergent laparoscopic repair of a Spigelian hernia: case report and review of the literature. Case Rep Med 2013; 2013: 197561. [CrossRef]

11. Coşkun A, Eryılmaz R, Güzey D, Daşıran F, Şahin M. Spigelian hernia: Diagnosis treatment. Ulus Cerrahi Derg 2006; 22: 137-139. 